\title{
ВЗАИМОСВЯЗЬ КОНЦЕПЦИИ «ОТВЕТСТВЕННОСТИ ПО ЗАЩИТЕ» С КОНЦЕПЦИЕЙ «ГУМАНИТАРНОЙ ИНТЕРВЕНЦИИ»
}

\begin{abstract}
Аннотация. Предметом исследования является концепиия «ответственности по защите», основные положения которой содержатся в ее базовом документе - Аокладе Международной комиссии по вмешательству и государственному суверенитету (МКВГС) (2002). В аспекте проводимого автором исследования концепция «ответственности по защите» трактуется в качестве смягченного варианта конщепции «гуманитарной интервенции». В предмет исследования включен также сравнительный анализ концепций «гуманитарной интервенции» $и$ «ответственности по защите» с позиции противоречивости юридического принципа суверенитета государства и нравственного императива защиты прав человека. Методы исследования: системного анализа, синтеза, аналогии, классификачии, исторический, сравнительно-правовой, систематический, структурно-функциональный, формально-логический, ^ингвистический, специальноюридический, Совокупность используемой методологической базы позволила гарантировать в итоге достоверность и обоснованность полученных выводов. Новизна работы заключается в выявлении автором того факта, что концепция «гуманитарной интервенции» противоречит международному праву, в то времл как конщепщия «ответственности по защите» является эвомючионным развитием данного направления международного права, при условии правильного ее применения на международной арене, что требует выработки критериев практической реализации данной концепции мировым сообществом.
\end{abstract}

Ключевые слова: международное право, концепиия ОПЗ, гуманитарная интервенция, внешнее вмешательство, вооруженное вмешательство, вмешательство в суверенитет, гуманитарные действия, защита своих граждан, защита прав человека, государственный суверенитет

Review. The subject of this research is the "Responsibility to Protect" concept, the key positions of which are contained in its basic document - the Report of the International Commission on Intervention and State Sovereignty (2002). The author interprets the "Responsibility to Protect" doctrine as a moderate version of the concept of "Humanitarian Intervention". The author also conducts a comparative analysis of these two concepts from the perspective of controversy of the legal principle of state sovereignty and the moral imperative of protecting human rights. The scientific novelty consists in revelation of the fact that the concept of "Humanitarian Intervention" contradicts the international law while the "Responsibility to Protect" doctrine, if properly implemented on the international arena, represents the evolutionary development of this direction of international law, which requires devising criteria for practical realization of that concept by the global communit.

Keywords: international law, "Responsibility to Protect» concept, humanitarian intervention, external intervention, armed intervention, interference in sovereignty, humanitarian actions, protection of citizens, protection of human rights, state sovereignty

овременное состояние мирового сообщества, характеризующееся гмобализацией и присущими ей вызовами, побужАает межАународное право к Аальнейшему развитию, уточнению и пересмотру основопомагающих институтов - таких, как государство, суверенитет, права человека. Проблемы межАународного мира и безопасности оказались выдвинуты в межаународном сообществе на первый план, и стремление преАотвратить опасности межАународного терроризма, оружия массового уничтожения, геноциАа и разАичного 


\section{НАЦИОНААЬНАЯ БЕЗОПАСНОСТЬ}

рода гуманитарных катастроф привело к формумировке в самом начаме нового XXI века новой концепции, занимающей все более важное положение в системе международного права.

Концепцию «ответственности по защите» можно трактовать в качестве смягченного варианта концепции «гуманитарной интервенции». Она выступает достаточно взвешенно к разрешению комлизионного соотношения государственного суверенитета и соблюдения прав человека. В то же время не в полной мере оформленный статус концепции, нерегламентированное закрепление оснований ее применения, ее трактовка как «формирующаяся норма» межАународного права оставляют широкое поле Аеятельности Аля специалистов в этой области.

Сегодня понятие «ответственности по защите» Аостаточно широко вошио в политическую мексику [13]. По мнению большинства исслеАователей, право на внешнее вмешатемьство Аолжно возникать не в одностороннем порядке, а в случае принятия решение группой государств [14].

В этой связи появляется немало важных проблем, в частности речь илет о законности вмешательства, его целесообразности, полномочиях сторон, осуществляющих его, а также о нарушении целостной системы национальной безопасности. В Аанном случае возникает вопрос о защите прав человека в суверенном государстве путем применения внешнего вмешатемьства [9].

Концепции «гуманитарной интервенции» и «ответственности по защите» явмяются важными понятиями современного межАународного права, отражающими очевиАное противоречие межАу юридическим принципом суверенитета государства и нравственным императивом защиты прав чемовека. На Аанный момент нельзя считать, что баманс межАу правомочностью и обоснованностью вмешательства в права государства найден ни на теоретико-правовом, ни на политико-практическом уровне. Вместе с тем обе концепции находят применение в межАународной политике, и наиболее актуацьной задачей современного межАународного права видится точное определение, ограничение функций и общее обоснование возможности и/ или необходимости применения к той или иной ситуации Аействий, связанных с «гуманитарной интервенцией » ими «ответственностью по защите».
- $5(40) \cdot 2015$

Ао сих пор отечественные специалисты по межАународному праву сравнитемьно мало внимания удемяли концепциям «гуманитарной интервенции» и «ответственности по защите», в то время как в запаАной доктрине вопросы обоснования вмешатемьства в суверенитет Аругого государства изучаются в течение многих $е$ ет.

Актуальность Аанных вопросов возросла в конце XX века в связи, в частности, с обращением Генерального секретаря ООН Кофи Аннан к мировой общественности с новым термином «ответственности по защите» мирного населения от беАствий войны в соответствии с нормами межАународного права: «Если гуманитарная интервенция Аействительно является неприеммемым ущемлением суверенитета, то как тогАа отвечать на такие ситуации, как Сребреница и Руанда - грубые и систематические нарушения прав человека, которые противоречат всем правилам человеческого бытия?» [цит. по: 8].

Реализация Аанных концепций, в современных условиях четкого определения и обоснования, явмяется весьма угрожающим инструментом возможного политического вмешательства. Обе концепции могут, в потенциале, становиться основанием Аля «цветных революций», стать поводом Аля «легитимного» вмешательства во внутренние Аела в узкокорыстных национальных интересах отдельных государств. Последовательная реализация Аанных концепций в указанном виде способна повлечь за собой подрыв межАународного права как юридического базиса современной системы межАународных отношений.

Вместе с тем в идеологии миберального ЗапаАа ведущим аспектом обсуждения проблемы применимости Аанных концепций становится аспект не юридический, а нравственный. Так, М. Уолцер - виАный философ, занимающийся вопросами этики и войны, весьма эмоционально замечает: «Bсе государства заинтересованы в глобальной стабильности и Ааже в глобальной человеческой общности, $<\ldots>$ стоит $\Lambda$ ишь сэкономить на нравственной цене молчания и безразличия <к житемям отАаленных стран>, и вам придется заплатить политическую цену потрясений и беззакония у вас Аома, ибо разве благопристойность может Аолгое время поААерживаться зАесь, если ее уже Аавно нет там?» $[15$, с. 74-75]. ОчевиАно, что 


\section{ТРАНСФОРМАЦИИ СИСТЕМ НАЦИОНААЬНОЙ БЕЗОПАСНОСТИ}

влиятельный иАеолог использует фрейм «заражения», когАа «потрясения и беззакония» могут мегко переходить из страны в страну.

Обе концепции, явмяя собой крайне Аискуссионные и противоречивые явления, соответственно, не имеют четкого политико-правового определения. На нынешнем этапе сложилась такая ситуация, что ни государства, ни международные политико-правовые институты, ни ученые не могут прийти к какой-Аибо согласованной и Аостаточно опреАеленной позиции по этому вопросу. А следовательно, обе концепции нужАаются в глубоком и взвешенном теоретическом анализе и Аальнейшем обосновании, при учете того что сфера их реализации как серьезных и влиятемьных концепций современного межАународного права отражает тенденцию к расширению.

Понятие «вооруженное вмешательство с цемью защиты прав человека» или «гуманитарная интервенция > в оборот ввеки профессор межАународного права Марио Беттати и одним из основателей широко известной организации «Врачи без границ» - французский помитик Бернар Кушнер (конец 1980-х гг.). Аанным термином определялись операции, что проводились в Гаити, Боснии и Герцеговине, Сомали и Аругих странах. С тех пор Аанный термин широко используется в политическом мексиконе.

Возможность формирования Аанного понятия была Аетерминирована помитической ситуацией, пришеАшей на смену «холодной войне»; оАнако после некоторых из операций, провеАенных в рамках реализации Аанной концепции, была осознана спорность Аанного понятия и необходимость его дахьнейшего уточнения.

Весьма полное определение приведено в сетевой энциклопедии: «Гуманитарная интервенция или гуманитарная война - применение военной силы против иностранного государства или каких-либо сия на его территории аля предотвращения гуманитарной катастрофы или геноциАа местного населения» [3]. В этой же статье уточняются явцения, не подпаАающие поА понятие гуманитарной интервенции (рис. 1). В виде мотиваций выведены «гуманитарная катастрофа» и «геноциА», что приближает Аанное определение к его пониманию в концепции «ответственности по защите».

\begin{tabular}{|l|l|}
$\begin{array}{l}\text { миротворческие } \\
\text { операции, про- } \\
\text { водимые ООН } \\
\text { с согласия государ- } \\
\text { ства, на террито- } \\
\text { рии которого они } \\
\text { предпринимаются }\end{array}$ \\
$\begin{array}{l}\text { акции принуди- } \\
\text { тельного характера, } \\
\text { не включающие } \\
\begin{array}{l}\text { использование воо- } \\
\text { руженной силы }\end{array}\end{array} \mid \begin{array}{l}\text { военные операция, } \\
\text { предпринимаемые } \\
\text { государством с целью } \\
\text { спасения своих граж- } \\
\text { дан за рубежом от не- } \\
\text { минуемой угрозы их } \\
\text { жизни или здоровью }\end{array}$ \\
$\begin{array}{l}\text { акции с исполь- } \\
\text { зованием воору- } \\
\text { женной силы по } \\
\text { просьбе законного } \\
\text { правительства }\end{array}$ \\
\hline
\end{tabular}

Рисунок 1. Явления, не подпадающие под понятие гуманитарной интервенции

Принятые в отечественной науке опредемения «гуманитарной интервенции», таким образом, виАят в ее концепции силовое вмешательство госуаарства или группы государств в поАитику Аругого государства, Аопускаемое при определенных обстоятельствах (среди которых названы нарушение прав и свобод человека, тоталитаризм, гражАанская война, геноцид и гуманитарная катастрофа) и проводимое при особых условиях (без санкции ООН, без согласия страны, насицьственность). Ааже краткий (в рамках Аанной статьи) анализ позволяет увидеть разночтения в определении феномена, который уже в течение Алительного времени занимает важное место в политической и правовой практике многих стран мира.

Явцяясь популярным термином, в то же время концепция «гуманитарной интервенции» не зафиксирована как официальное понятие в межАународных актах современности, в том числе в общих (универсальных), мокальных или Авусторонних межгосуаарственных договорах. Аругими словами, этот термин не является термином современного межаународного права. Именно поэтому понятие «гуманитарной интервенции» Ао сих пор остается размытым, а его определения множатся без уточнения сути определяемого явмения. По сути отсылки помитических деятелей к праву на «гуманитарную интервенцию» явмяются неправомочными в сику неопределенного статуса Аанного явмения.

Неопределенность термина «гуманитарная интервенция $\gg$ и, фактически, его противоречие нормам международного права привели мировое сообщество к поиску Аругих концепций, спо- 


\section{НАЦИОНААЬНАЯ БЕЗОПАСНОСТЬ}

собных обосновать возможность вмешательства в политику государства извне.

Отчасти эти цели преследовала созданная в сентябре 2000 г. МежАународная комиссия по вопросам вмешательства и государственного суверенитета. По результатам анализа оснований Аля мегитимации «гуманитарных интервенций» ей бым преАставлен доклаА «Ответственность по защите» на рассмотрение Генерамьного секретаря и чиенов Организации Объединенных Наций (2001). Международными экспертами были ввеАены понятия «ответственность по защите» ими «ответственность за защиту» («responsibility to protect» ики «R2P»). Кроме того они призвали в большей степени учитывать интересы постраАавших от войн и насимия гражАанских миц, которые обязано обеспечивать их государство или, в случае его неспособности или нежелания, - межАународное сообщество государств.

Фактически в Аоклале было сказано о том, что «ответственность по защите» - вариант «права на вмешательство», но принципиально новый. Предлагаемая концепция вносияа коррективы в традиционное понимание государственного суверенитета, трактуя его не только с позиции наличия у государства прав, но и обязанностей. Изменение терминологии, по мнению авторов доклаАа, «помогает перенести фокус Аискуссии туАа, гАе он и Аолжен находиться - на потребности тех, кто ищет помощи и нужАается в ней» [5]. Авторы АоклаАа призвали уточнить политические цели, вести политический контроль, соблюдать нормы межАународного права при поАготовке операций в соответствии с «ответственностью по защите». ВеАение одобрения операций по реализации новой концепции Советом Безопасности ООН следует признать важнейшим отличительным требованием.

Итоговый Аокумент Всемирного саммита 2005 года также утверждац важность ответственности по защите: «МежАународное сообщество, Аействуя через Организацию ОбъеАиненных Наций, обязано $<\ldots>>$ содействовать защите населения от геноцида, военных преступлений, этнических чисток и преступлений против человечности. В этой связи мы готовы преАпринять коммективные Аействия, своевременным и решительным образом, через Совет Безопасности, в соответствии с Уставом <...> с учетом конкретных обстоятельств и в сотруаничестве с соответствующими региональными организациями, в случае необхоАимости, если мирные среАства окажутся неАостаточными, а национацьные органы власти явно окажутся не в состоянии защитить свое население от геноциАа, военных преступлений, этнических чисток и преступлений против человечности» [6].

Следовательно, одно из отличий концепции «ответственности по защите» от концепции «гуманитарной интервенции» состоит в максимахьной мегитимизации преАпринимаемых Аействий. Мировое сообщество настаивает на преАотвращении и прекращении массовых нарушений прав чемовека, что говорит о необходимости законодательного и идеологического закрепления форм защиты мюАей от противоправных Аействий.

АоклаА группы высокого уровня по угрозам, вызовам и переменам (2005) зафиксировах формирование новой нормы международного права по оптимизации работы Совета Безопасности в отношении массовых угроз: «Мы подаерживаем формирующуюся норму, предусматривающую, что существует комлективная международная ответственность за защиту, реализуемая Советом Безопасности, санкционирующим военное вмешательство в качестве крайнего средства в случае, когАа речь идет о геноциде и Аругих массовых убийствах, этнической чистке или серьезных нарушениях межАународного гуманитарного права, которые суверенные правительства не смогли или не пожелали предотвратить» [4].

Следует отметить неясность статуса «ответственности по защите» как таковой. ОАнако в 2011 году Генерамьный секретарь ООН Пан Ги Мун назвац концепцию «ответственности по защите» «новой нормой межАународной безопасности и прав человека, связанной с проявившейся ранее неспособностью межАународного сообщества предотвращать и прекращать геноциА, военные преступления, этнические чистки и преступления против человечности» [цит. по: 10 , с. 97]. В этой связи можно прогнозировать, что в будущем возможен перехоА концепции от статуса «нормы межАународной безопасности и прав человека» к статусу нормы межАународного права, что актуамизирует исследование воз- 


\section{ТРАНСФОРМАЦИИ СИСТЕМ НАЦИОНААЬНОЙ БЕЗОПАСНОСТИ}

можностей и принципов, раскрывающих понятие Аанной концепции.

В отличие от сравнительно подробно исслеАованного понятия «гуманитарной интервенции», концепция «ответственности по защите» весьма реАко становится объектом исслеАования в отечественной науке, хотя за рубежом эту концепцию обсуждают очень активно.

ОАним из крупных отечественных исследователей концепции «ответственности по защите» является В. С. Котмяр. Он называет концепцию, выАвинутую в докладе 2001 г., сбалансированной концепцией гуманитарной интервенции, хотя и указывает на определенную опасность змоупотреблений в этой сфере. Он приходит к выводу, что участившиеся гуманитарные катастрофы и массовые нарушения прав человека свидетельствуют о том, что «изменение норм межАународного права по этому вопросу, виАимо, Аействительно назрело» [7]. Позиция исследователя по поводу отношения России к Аанной концепции такова: «сегодня интересам России в большей степени соответствовало бы принятие - с необходимой модификацией - концепции «ответственности за защиту», чем ее отклонение $\gg$ [7]. В. В. Гаврилов справеАливо отмечает, что ответственность по защите «не может быть позиционирована как новая юридическая норма или принцип. Это скорее межАисциплинарная межАународная «маршрутная карта», обосновывающая и опреАеляющая перечень Аействий, которые государства и международное сообщество Аолжны преАпринимать в цемях защиты мирного населения с опорой на существующие юридические и политические принципы и нормы» $[1]$.

К. А. Сазонова, вслеА за В. С. Котмяром, указывает на важность понимания и применения Аанной концепции в межАународном праве Аля внешнеполитических интересов России, «в связи с чем преАстав яется необходимым УАелить более пристальное внимание анализу ее юридической составляющей с тем, чтобы не Аопустить зАоупотреблений силой при практической реализации Аанной концепции $\gg[10$, с. 100$]$.

Вопрос о соотношении Авух взаимосвязанных концепций верно выражен в статье М. Т. Гигинейшвили: «Если соотноситьконцепцию «ответственность за защиту» и гуманитарную интервенцию, то они соотносятся как целое и частное» [2, с. 32]. Крайней формой проявления ответственности по защите будет являться, так или иначе, вооруженное вмешательство. Вместе с тем такая возможность не Аает оснований Аля мегитимизации термина «гуманитарная интервенция», Ааже несмотря на мнение отдемьных западных ученых: «Уважаемые Ученые, судьи Межаународного суАа ООН Брюно Сима и Стивен Швебель говорят о возможности трансформации концепции «ответственность за защиту» и гуманитарной интервенции в межАународный обычай $\gg[2$, с. 32$]$.

Несомненно, необходимо размичать понятия «гуманитарная интервенция», «ответственность за защиту», «защита согражАан за рубежом» и т. А. Необходимо отАелить и исследовать как размичные политико-правовые феномены:

- неотъемлемое право государства на защиту своих гражАан, которые пребывают в опасности за рубежом;

- гуманитарные действия по защите человеческой жизни, когАа имеют место массовые нарушения прав человека [8].

Первый круг явмений преАполагает защиту гражАан, находящихся в опасности за рубежом. когАа государство использует суверенное право на вооруженную самооборону и защищает своих гражАан, чаще всего относительно небольшое количество.

В скучае гуманитарной интервенции, государство или межАународная организация преАпринимает вооруженные Аействия по защите гражАан Аругого госуаарства или государств Аля преАотвращения массовых нарушений прав человека.

Концепции «гуманитарной интервенции» и «ответственности по защите» обе предполагали и преАполагают мегитимное применение силы и правовое основание Аля вмешательства государства или группы государств во внутренние Аела суверенного государства. Вместе с тем важнейшим отличием межАу ними, на законодательном уровне, является более разработанный механизм контроля наА реализацией концепции ОПЗ, причем кмючевую роль зАесь играет СБ ООН как мегитимный орган, принимающий важнейшее решение.

Таким образом, «гуманитарная интервенция», как нестрого опреАеляемый и непоАкон- 


\section{НАЦИОНААЬНАЯ БЕЗОПАСНОСТЬ • 5 (40) • 2015}

трмьный ООН феномен противоречит межАународному праву (в первую очереАь, принципам невмешательства во внутренние дека, применение силы и угрозы симой, суверенитету, территориальной целостности, принципу мирного разрешения споров). Концепция «ответственности по защите» является эволюционным развитием Аанного направления межАународного права, это компромисс, ставящий во главу угла права $ю$ юей; но при расширитемьном толковании есть опасность применения и Аанной концепции в узкокорыстных национальных интеpecax, что может приводить к смене режимов и Аругим результатам, Аалеким от целей защиты прав чемовека.

В современном международном гуманитарном праве не сформировалось также и обычной нормы относительно «ответственности по защите» без полномочий Совета Безопасности ООН, поскольку, несмотря на наличие опреАеленного объема практики, международный обычай opinio iuris [12] так до сих пор и не был сформулирован.

Из-за многомерности подходов концепция «ответственности по защите» воспринимается и трактуется по-разному в различных правовых, политических и кумьтурных системах, что осложняет унификацию поАходов, методов и способов ее регулирования. Поэтому крайне необходимо нормативно закрепить эти составляющие концепции «ответственности по защите» при решении многих проблем, связанных с ними с целью избежания новых проблем [11]. Также большим заделом станет выработка критериев практической реализации Аанной концепции мировым сообществом. Наконец, в системе межАународных отношений и межАународного права в настоящее время проходят трансформации относительно восприятия их основополагающих принципов, что может породить абсолютно новые, и в определенной степени сложно контролируемые явления, что является нежелательным Аля мирового сообщества в целом.

\section{БИБАИОГРАФИЯ}

1. Гаврилов В. В. Соотношение и последовательность действий органов государства и межАународных организаций в рамках концепции «ответственность за защиту» в Азиатско-Тихоокеанском регионе Евразийский юридический журнал. 2010. № 12 (31). [Электронный ресурс]. - Режим Аоступа: http://www.eurasialaw.ru/index.php?option=com content\&view=article\&id=1611:-1-r-\&catid=194:2010-12-27-06-58-52\&Itemid=1

2. Гигинейшвили М. Т. Проблема обычно-правовой природы концепции «ответственность за защиту» // А^ьманах современной науки и образования.-2009.-№ 7 (26): в 2-х ч.-Ч. І.-С. 31-33.

3. Гуманитарная интервенция [Эмектронный ресурс].-Режим Аоступа: http://ru.wikipedia.org/ wiki/Гуманитарная_интервенция.

4. АоклаА группы высокого уровня по угрозам, вызовам и переменам [Экектронный ресурс].-Режим доступа: http://www.un.org/russian/secureworld/a59-565.

5. АоклаА МежАународной комиссии по вмешательству и государственному суверенитету [Электронный ресурс]. Режим доступа: http://daccess-dds-ny.un.org/doc/UNDOC/GEN/ N02/525/72/IMG/N0252572.pdf.

6. Итоговый документ Всемирного саммита 2005 года [Электронный ресурс]. - Режим доступа: http://www.un.org/ru/documents/decl_conv/declarations/outcome2005.shtml

7. Котмяр В. С. Концепция ответственности за защиту как проект кодекса проведения гуманитарных интервенций // МежАународное публичное и частное право. - 2005. - № 3. [Экектронный ресурс]. - Режим доступа: http://www.lawmix.ru/comm/776.

8. Крылов Н. Б. Гуманитарная интервенция: право или бесправие? // Евразийский юридический журнал. 2012. № 10 (53). [Эмектронный ресурс]. - Режим Аоступа: http://www. eurasialegal.info/index.php?option $=$ com_content $\&$ view $=$ article\&id $=1600: 2012-11-15-05-29-25 \&$ catid=116:2011-09-19-12-34-31\&Itemid=1.

9. Иукашук И. И. МежАународное право. Особенная часть. - М.: Волтерс-Клувер, 2008. - 544 с.

10. Сазонова К. $\Lambda$. Концепция «ответственность за защиту» в миротворческой деятельности организаций объединенных наций // Юридическая наука. - 2012. - № 1. - С. 96-101. 


\section{ТРАНСФОРМАЦИИ СИСТЕМ НАЦИОНААЬНОЙ БЕЗОПАСНОСТИ}

11. Evans, G. and M. Sahnoun (2002): 'The Responsibility to Protect', in: Foreign Affairs 81(6), pp. 99-110.

12. Huth, K. P. (1998): 'Major Power Intervention in International Crises, 1918-1988', in: The Journal of Conflict Resolution 42(6), pp. 744-770.

13. Power, S. (2002): "A Problem from Hell": America and the Age of Genocide, New York: Basic Books.

14. Ratner, S.R. (2000): 'Does International Law Matter in Preventing Ethnic Conflict?', in: New York University Journal of International Law and Politics 32, pp. 591-698.

15. Walzer M. Arguing About War. New Haven. L.: Yale University Press, 2004. P. 74-75.

\section{REFERENCES}

1. Borshchevskii G. A. Rol' gosudarstva $\mathrm{v}$ formirovanii preemstvennogo istoricheskogo soznaniya $\mathrm{v}$ kontekste problemy obespecheniya natsional'noibezopasnosti Rossii / Informatsionnyigumanitarnyi portal «Znanie. Ponimanie. Umenie». — 2012. — № 1 (yanvar’ — fevral').

2. Glushchenko V. V. Riski innovatsionnoi i investitsionnoi deyatel'nosti v usloviyakh globalizatsii.-g. Zheleznodorozhnyi, Moskovskaya oblast': OOO NPTs Kryl'ya, 2006. - 230 s.

3. Glushchenko V. V. Korporatsii kak sub"ekty upravleniya geopoliticheskim riskom investitsionnoi deyatel'nosti v usloviyakh globalizatsii//Vestnik GUU,№1 (14), 2006,s. 201-212

4. Glushchenko V. V. Gosudarstvo kak geopoliticheskaya publichnaya korporatsiya v usloviyakh postindustrial'nogo global'nogo mira//Natsional'nye interesy: prioritety i bezopasnost' № 7(16), 2007.

5. Glushchenko V. V. Geopolitikologiya kak nauchnaya osnova geopoliticheskogo prognozirovaniya// Mezhdunarodnyi nauchno-issledovatel’skii zhurnal, № 7 (38), 2015, Chast’ 4, Avgust, s.83-90.

6. Kuznetsov V. N. Geokul'tura. Osnovy geokul'turnoi dinamiki bezopasnosti v mire XXI. - M.: Kniga i biznes, 2003. - S. 8.

7. Sergeev V. M., Kazantsev A.A. Struktury mirovogo poryadka: istoricheskaya tipologiya//Kosmopolis. - 2008. - №1(20).

8. Bzhezinskii Z. Velikaya shakhmatnaya doska. Gospodstvo Ameriki i ego geostrategicheskie imperativy. - M.: Mezhdunarodnye otnosheniya, 2003. $-250 \mathrm{~s}$.

9. Glushchenko V.V. Gosudarstvologiya i pravologiya (nauka o gosudarstve i prave-obshchaya teoriya gosudarstva i prava): krizisologiya gosudarstva, gosudarstvennoe antikrizisnoe upravlenie.-M.: IP Glushchenko Valerii Vladimirovich, $116 \mathrm{~s}$.

10. Sapozhnikova N.T. Protsess globalizatsii i mezhdunarodnye monopolii / Sovremennaya teoriya globalizatsii: ekonomicheskie ocherki. - M.: GUU, 2002, s.63-75.

11. Gosudarstvennoe upravlenie v 21 veke: povestka dnya rossiiskoi vlasti:10-ya Mezhdunarodnaya nauchnaya konferentsiya fakul'teta gosudarstvennogo upravleniya MGU im. M.V. Lomonosova, 2931 maya 2012 g.Materialy v 3 ch.: Chast' 1.-M.: Izdatel'stvo Moskovskogo universiteta, 2013.-736 s.(materialy konferentsii).

12. Kordonskii S. Klassifikatsiya i ranzhirovanie ugroz// Otechestvennye zapiski, 2013, №2(53)

13. Strategii natsional'noi bezopasnosti RF do 2020 goda//http://www.scrf.gov.ru/documents/99.html/ 